\title{
O enfermeiro não faz marketing pessoal: a história explica por Quê?
}

\author{
Nurses are not into personal marketing: do history explain why? \\ Enfermeros no hacen marketing personal: la historia lo dice por Qué?
}

\author{
Rosana Chami Gentil' \\ 'Universidade Federal de São Paulo. Departamento de Enfermagem. São Paulo, SP
}

Submissão: $12 / 12 / 2008$

Aprovação: 30/06/2009

\section{RESUMO}

Reflexão sobre o marketing pessoal do enfermeiro embasado nas crenças e valores Que a história dos protagonistas do cuidado ao enfermo explica. Traz à tona reflexões sobre a ambigüidade entre a imagem social da enfermagem e os conhecimentos científicos, tecnológicos e humanísticos Que desenvolveu ao longo do tempo. Reconhece Que ainda há fixação nos atributos relativos à postura e moral dos profissionais, em detrimento da valorização do conhecimento técnico-científico. Constata Que o estudo da História da Enfermagem leva a compreender Que as lutas travadas contra os preconceitos presentes no imaginário coletivo têm importância na aceitação e reconhecimento social dessa profissão e Que o caminho para isso está na divulgação da Ciência da Enfermagem e demonstração de sua aplicação na prática profissional Descritores : História da enfermagem; Marketing; Prática profissional.

\section{ABSTRACT}

Reflection on the nurse's personal marketing based on beliefs and values explained by the history of the main characters that care for patients. It brings to the surface reflections on the ambiguity between the social image of nursing and scientific, technological and humanistic knowledge developed over the time. It recognizes that there is still a fixation on the attributes relating to attitude and moral of the professionals to the detriment of having high regard for the technical and scientific knowledge. It verifies that the History of Nursing allows understanding that the fight against prejudice in the collective imagination lends weight to the social acceptance and recognition of this profession through the promotion of Nursing Science and the demonstration of its application in the professional practice.

Descriptors: History of Nursing; Marketing; Professional practice.

\section{RESUMEN}

Reflexión sobre el marketing personal del enfermero basado en las creencias y valores que la historia de los protagonistas del cuidado al enfermo explica. Saca a flote reflexiones sobre la ambigüedad entre la imagen social de la enfermería y los conocimientos científicos, tecnológicos y humanísticos Que desarrolló a lo largo del tiempo. Reconoce que todavía hay fijación en los atributos relacionados con la postura y moral de los profesionales, en detrimento de la valoración del conocimiento técnico-científico. Constata Que el estudio de la Historia de la Enfermería permite comprender Que las luchas contra de los perjuicios existentes en la imaginación colectiva tiene importancia en la aceptación y en el reconocimiento social de esta profesión, lo Que puede hacerse promocionando la Ciencia de la Enfermería y demostrando su aplicación en la práctica profesional.

Descriptores: Historia de la Enfermería; Mercadeo; Práctica profesional. 


\section{INTRODUÇÃO}

A dificuldade do enfermeiro em falar da sua capacidade profissional sempre me incomodou porQue eu não conseguia entender, e também tinha dificuldade em falar da minha capacidade profissional.

Foi pesquisando e conhecendo a história da enfermagem Que comecei a entender porQue o enfermeiro não faz marketing pessoal.

Marketing pessoal hoje é a ferramenta mais eficiente para fazer com Que seus pensamentos e atitudes, sua apresentação e comunicação, trabalhem a seu favor no ambiente profissional. As empresas analisam muito mais do Que sua experiência profissional, seu capital intelectual e a ética, Que são fundamentais na definição do perfil daqueles Que serão parceiros/colaboradores ${ }^{(1)}$. Marketing pessoal pode ser definido como "uma estratégia individual para atrair e desenvolver contatos e relacionamentos interessantes do ponto de vista pessoal e profissional, bem como para dar visibilidade a características, habilidades e competências relevantes na perspectiva da aceitação e do reconhecimento por parte de outros"(2).

O caminho para o sucesso é a prática do marketing pessoal por meio de alguns elementos como as emoções positivas, Que remetem à imagem de outrem, como atenção, simpatia, assertividade, ponderação, sinceridade e demonstração de interesse pelo próximo, de forma autentica e transparentes; a comunicação interpessoal, a rede de relacionamento, o posicionamento de imagem, Que pode ser definida como uma adeQuação visual ao contexto social e, por último, a prática de ações de apoio, ajuda e incentivo para com os demais, Que é o grande elemento do marketing pessoal e a melhor forma de galgar um lugar nas mentes e corações dos Que nos cercam ${ }^{(2)}$.

Uma pessoa Que possua talento e competência suficiente para exercer a sua atividade, desde Que pratiQue e aperfeiçoe constantemente o seu marketing pessoal, pode chegar ao topo, elevando o seu nível de notoriedade e imagem, recompensa por essa tarefa Que exige paciência, disciplina, perseverança, uma elevada auto-estima, determinação e um conjunto de crenças e valores Que irão nortear suas atitudes e comportamentos, de forma a fazer uso correto das habilidades inatas e das habilidades a serem criadas e aperfeiçoadas ${ }^{(3)}$.

A maior parte das pessoas tem dificuldade para falar de sua capacidade profissional. Para elas estar em evidência não é uma pratica saudável, muito menos profissional. Vivem feito ostras, achando Que cabem aos outros o esforço de encontrar as pérolas Que existem no interior de suas cascas. Mal elas sabem Que, diante do mundo extremamente competitivo, esse tipo de comportamento não tem mais lugar. Ou elas assumem a postura de Que para sobreviver profissionalmente precisam fazer com Que todos saibam Quem elas são, ou, então acabarão vendo suas carreiras irem por água abaixo ${ }^{(4)}$.

Para o enfermeiro em particular, essa dificuldade de falar de sua capacidade profissional advém de alguns conceitos ultrapassados, como crer Que a ascensão social do indivíduo é uma consequência natural do aumento do grau de instrução Que ele adQuire e da cristalização de crenças e valores que a história dos protagonistas do cuidado ao enfermo explica, como euando se faz a leitura do profissional pela classe social e não pela competência, não considerando o enfermeiro como um profissional autônomo e com nível superior.

No inicio do século XVI, houve um período chamado de crítico Quando, com a Reforma Protestante, alguns países expulsaram religiosas dos hospitais em renúncia ao catolicismo. Dessa forma, muitos hospitais tiveram Que contratar mão-de-obra desQualificada e com baixa remuneração. Assim, a enfermagem passa a ser exercida por mulheres de moral duvidosa (prostitutas, alcoolistas, analfabetas). O cuidado com o corpo humano foi estabelecido pelo rompimento entre os conceitos de sagrado e profano, estabelecido pelo cristianismo, impossibilitando o acesso a áreas "proibidas", como os órgãos sexuais ${ }^{(5,6)}$.

A formação da enfermeira era "dualista": por um lado exercida por mulheres leigas, mercenárias, subornáveis, prostitutas e, por outro lado, religiosas e senhoras de caridade, devotadas, bondosas, caridosas, assexuadas e virgens, dedicadas à filantropia, Que barganhavam a salvação através da prática do cuidar, onde o corpo, apesar de fonte de corrupção e fornicação, ao mesmo tempo não poderia ser afastado porQue era suporte aos cuidados espirituais ${ }^{(7)}$.

A enfermagem moderna, com as suas bases de rigor técnico e científico, começou a se desenvolver no século XIX, através de Florence Nightingale, acompanhada pela enfermeira negra jamaicana Mary Grant Seacole, Que estruturou seu modelo de assistência depois de ter trabalhado no cuidado com soldados durante a guerra da Criméia. Ao criar a primeira escola para enfermeiras, Florence teve, como objetivo principal, afastar a imagem das enfermeiras leigas, preocupando-se principalmente com a origem socio-econômica e conduta moral das alunas e em estabelecer a imagem da enfermeira como anjo branco, abnegada, submissa, intocável e sagrado-cristẫ ${ }^{(5,7)}$.

Já no Brasil, no período colonial, durante mais de três séculos todo o cuidado as pessoas doentes, foi fundamentalmente realizado por escravos ${ }^{(6)}$. Porem no início do século XX, a enfermagem que era exercida por homens e mulheres, se tornou predominantemente feminina, assumindo-se a comparação das atividades de enfermagem às Qualidades e habilidades consideradas inatas às mulheres como verdade social daquelas pessoas. No final dos anos 80 e inicio dos 90 com os estudos sobre as Questões de gênero e da sexualidade de Quem cuida e de Quem é cuidado, começou-se a pensar numa história diferente da oficial, aQuela história branca, machista e elitista Que demarcou poderes e limitou ações ${ }^{(7)}$.

A enfermagem é uma profissão alimentada por ambigüidades, dando a impressão de Que fizemos a nossa história perseguindo opostos: anjo branco/prostituta, mãe/amante, Florence Nightingale/ Sairey Gamp, rica/pobre, branca/negra, moça de boa família/ moça de família duvidosa, enfermagem não tem sexo/personagem de filme pornográfico, docente/assistencial, vestida de uniforme/seminua de lingerie $\operatorname{preta}^{(7)}$.

A enfermagem antiga se respaldava na solidariedade humana, no misticismo, no senso comum e em crendices. Atualmente, procura aprofundar seus conhecimentos científicos, tecnológicos e humanisticos tendo, como centro de suas atividades, cuidar da saúde do ser humano. Mas ainda a realidade profissional se descaracteriza Quando nós enfermeiros não somos "chefes" ou "enfermeira padrão", somos frequentemente confundidos com outros profissionais da enfermagem ou classificados como " ajudantes" ou "secretaria de médico", ou Quase medicos. Assim ainda há a necessidade de supervalorização da postura e da moral dos profissionais, em detrimento do conhecimento técnico ${ }^{(8)}$.

\section{Que tal mudar alguns velhos paradigmas e repensar o nosso próprio Marketing Pessoal?}

O marketing pessoal na enfermagem carrega consigo os desafios representados pela história da profissão no imaginário coletivo. Nosso 
cuidado é sensual, isto é, realizado pelos órgãos do sentido. A vestimenta inadequada remete à sexualidade, por isso, de forma inconsciente, fica estabelecido, pelo profissional e pelo paciente, um limite de atuação e a impressão de ser um profissional assexuado ${ }^{(9)}$.

Para $\operatorname{Rosa}^{(10)}$ "saber trabalhar sua imagem é uma competência em si, e deve ser desenvolvida para fazer seu trabalho aparecer; então, preste atenção em como você está sendo visto em seu emprego e assuma o controle de sua imagem".

De acordo com Guilhermo ${ }^{(I I)}$, a disposição para organizar sua história, a apresentação pessoal por meio de vários tipos de currículos, currículo completo, comprovado e resumido, deve ser cuidado, como cuidamos dos pacientes ou clientes. O cartão pessoal e o site pessoal são formas de apresentação pessoal, com custo baixo e necessário no mundo contemporâneo. O empreendedorismo, a coragem em experimentar coisas novas, assumir riscos, ir a lugares Que não se foi antes, expandir relacionamentos, enfim, os profissionais precisam estar conectados, saber localizar informações e serem facilmente localizados.

Em entrevista pelo Conselho Regional de Enfermagem de Goiás, Persona $^{(4)}$ fala sobre marketing para profissionais de saúde: "Creio Que o produto do profissional de saúde não são apenas suas habilidades, mas ele próprio, tudo o que é e sabe fazer. O profissional de saúde é, antes de tudo, um profissional do conhecimento. O Que ele vende é o que sabe sobre o cuidar de um cliente, e é preciso entender o Que esses clientes esperam dele. Ele é o seu próprio outdoor, é ele o comercial na TV, é ele a página da revista. Trabalhar essa postura humana é o primeiro passo e talvez o mais importante para um profissional. Cabe ao profissional planejar cuidadosamente seu marketing pessoal, trabalhar sua pessoa e criar uma imagem Que seja um espelho de suas Qualidades".

Para o enfermeiro é muito difícil criar uma imagem Que seja um reflexo de sua Qualidade. Não Que o enfermeiro não possua Qualidades; ele tem consciência delas, mas porque tem inculcado, de forma até inconsciente, Que seu trabalho é caridade, abnegação, portanto, não é passível de ser divulgado, e muito menos como marketing pessoal.

Por outro lado é preciso ter cuidado para que o marketing pessoal, não seja só aparência de um bom profissional, pois de acordo com Shinyashiki ${ }^{(12)}$ "heróis de verdade são aqueles que trabalham para realizar seus projetos de vida, e não para impressionar os outros. É pena Que a maior parte das pessoas esconda suas raízes. O mundo corporativo virou um mundo de faz de conta, a começar pelo processo de recrutamento. É contratado o sujeito com mais marketing pessoal. As corporações valorizam mais a auto-estima do que a competência. Falta às pessoas a verdadeira auto-estima. Hoje, como as pessoas não conseguem nem ser nem ter, o objetivo de vida se tornou parecer. As pessoas parecem Que sabem, parecem Que fazem, parecem Que acreditam. Como as pessoas podem se livrar da tirania da aparência? O primeiro passo é pensar nas coisas Que fazem as pessoas cederem a essa tirania e tentar evitá-las. São três fraquezas: a primeira é precisar de aplausos, a segunda é precisar se sentir amada e a terceira é buscar segurança. $\mathrm{O}$ Que as escolas deveriam fazer é ajudar o aluno a desenvolver suas próprias potencialidades".

Somos todos responsáveis em construir a nossa própria história. Portanto, é imprescindível Que os profissionais sejam capazes de identificar e refletir sobre os pré-juízos e tradições Que perpetuam na Enfermagem, no sentido de superá-los. Trabalhar a postura humana e profissional é o primeiro passo, e talvez o mais importante, para melhorar o marketing do enfermeiro junto a sociedade ${ }^{(5)}$.

Como se constatou, o estudo da história da enfermagem leva a compreender Que as lutas travadas contra os preconceitos impostos pelo imaginário coletivo, através do conhecimento, têm importância na aceitação e reconhecimento dessa profissão.

\section{REFERÊNCIAS}

1. Wikipedia. Marketing pessoal. [citado em 6 jun 2008]. Disponível em: http://www.pt.wikipedia.org/

2. Jesus SL. O Que é marketing pessoal? [citado em 6 jun 2008]. Disponível em: http://www.mulheresdeclasse.com.br/

3. Doin E. O marketing pessoal na sua trajetória profissional. [citado em 6 jun 2008]. Disponível em: http://www.mulheres declasse.com.br/

3. Persona M. Marketing para profissionais de saúde. Rev Foco COREm-GO. [citado em 6 jun 2008]. Disponível em: http:// www.mariopersona.com.br

4. Colpo IC, Camargo VC, Mattos SA. A imagem Corporal da enfermeira como objeto sexual na mídia: um assédio a profissão. Cogitare Enferm 2006; I I (1): 67-72.

5. Souza CA. Poderíamos afirmar Que a essência do cuidador do enfermo ou a Enfermagem advém de pessoas amorais? In: Anais do VII Congresso Brasileiro dos Conselhos de Enfermagem Rio de Janeiro (RJ), Brasil. Rio de Janeiro: COREn-RJ; 2004.
6. Cruz ICF, Sobral VRS. Nem Ladies, nem Nurses: Sinhazinhas e Mucamas. Por uma re-visão da história da enfermagem brasileira (e do Sistema de Saúde). In: IV Semana Científica de Enfermagem da Escola de Enfermagem da Universidade Federal Fluminense. Niterói (RJ, Brasil. Niterói: Universidade Federal Fluminense; 1994.

7. Sataciarini IM, Andraus LMS, Esperidião E, Nakatani AK. Quem é o enfermeiro? Rev Eletrônica Enferm 1999; I(I).

8. Galante AC. O Profissional de Enfermagem perante uma Questão de sexualidade. Rev Centro Universitário Barão de Mauá 200 I; I (2).

9. Rosa IA. Trabalhe sua imagem. [citado em 6 jun 2008]. Disponível em: http://www.mulherdeclasse.com.br/.

10. Guilhermo A. Marketing pessoal na enfermagem. [citado em 6 jun 2008]. Disponível em: http://www.brasilmedicina.com.br/ noticias/pgnoticias

11. Shinyashiki R. Marketing para profissionais de Saúde. [citado em 6 jun 2008]. Disponível em: http://www.sobragen.org.br/ entrevista.htm 